\title{
Examine the Relationship of Emotional Intelligence and Creativity with Academic Achievement of Second Period High School Students
}

\author{
Hossein Jenaabadi' ${ }^{1}$ Razieh Shahidi' ${ }^{2}$, Abdolhamid Elhamifar ${ }^{3}$, Hamideh Khademi ${ }^{3}$ \\ ${ }^{1}$ Department of Education, University of Sistan and Baluchestan, Zahedan, Iran \\ ${ }^{2}$ Payame Noor University, Zahadan, Iran \\ ${ }^{3}$ Department of Psychology, Islamic Azad University, Zahedan Branch, Zahedan, Iran \\ Email: hjenaabadi@ped.usb.ac.ir
}

Received 25 November 2014; accepted 14 March 2015; published 30 July 2015

Copyright (C) 2015 by authors and Scientific Research Publishing Inc.

This work is licensed under the Creative Commons Attribution International License (CC BY). http://creativecommons.org/licenses/by/4.0/

(c) (i) Open Access

\begin{abstract}
The present study aimed to examine the relationship of emotional intelligence and creativity with academic achievement of second period high school students in Nikshahr. This was a descriptive-correlational study. The population of the current study included all second period high school students in the academic year of 2013-2014. The statistical sample was selected using simple random sampling method. To collect data, Mayer Salovey Caruso Emotional Intelligence Test (1995) as well as Creativity Questionnaire (Sultani) and to compare students' academic achievements, their GPAs in the academic year of 2013-2014 were used. Obtained data were analyzed using both descriptive (frequency table, frequency, and charts) and inferential statistics (independent t-test and Pearson correlation coefficient). The results indicated that emotional intelligence and academic achievement were significantly correlated. Moreover, there was a significant and positive relationship between creativity and academic achievement. Additionally, no significant difference was found between males and females considering their academic achievement.
\end{abstract}

\section{Keywords}

Emotional Intelligence, Creativity, Academic Achievement, Second Period High School Students

\section{Introduction}

Emotional intelligence is the ability to understand our and others' feelings and emotions through applying which

How to cite this paper: Jenaabadi, H., Shahidi, R., Elhamifar, A. and Khademi, H. (2015) Examine the Relationship of Emotional Intelligence and Creativity with Academic Achievement of Second Period High School Students. World Journal of Neuroscience, 5, 275-281. http://dx.doi.org/10.4236/wins.2015.54025 
one can communicate more effectively with others. In other words, emotional intelligence is a set of knowledge and social and emotional skills that impact our overall capabilities in response to environmental needs creating a sense of responsibility in the face of intense emotions through using the ability to understand ourselves and others and applying self-awareness, self-management, social awareness and relationship management which enable us to adapt to changes and solve individual and social problems. According to Goleman, compared to other features, such as Intelligence Quotient (IQ) or technical skills, emotional intelligence plays a more prominent role in having a favorable performance. In this regard, IQ is considered as one's minimum achievement and EQ is regarded as his/her maximum success. Emotional intelligence means perception and management of our and others' feelings applying emotions to guide thought. Meanwhile, since educational and training system is responsible for educating children who make the future of a society, on one hand, it should provide an appropriate situation which aids children to grow and develop their creativity and innovation and teach them to properly use their talents and capabilities, and on the other hand, for its dynamics, it needs to develop and take advantage of creativity and innovation in organizational levels [1].

Today, it has proved that unlike many beliefs considering innovation and creativity as inherent characteristics, these traits are common among all human beings like memory and can be fostered and developed using specific principles and techniques and providing a favorable environment. While creativity means creating new and original thoughts and ideas, looking differently, and exploring and developing new solutions to solve an issue, innovation means the process of acquiring creative ideas and converting them into products and services and/or a useful operational method. Teachers and instructors play a key role in identifying students' interests and developing creativity and innovation, since if this force which is actually the main energy generator in the society is neglected, education and training system will become weaker and weaker and stop working [2].

Considering what was mentioned earlier, the main issue of the current study was to answer this question: how is the relationship of emotional intelligence and creativity with academic achievement of second period high school students in Nikshahr?

The overall goal of this study was to identify the relationship of emotional intelligence and creativity with academic achievement of second period high school students in Nikshahr and its other objectives were:

1) Identifying the relationship between emotional intelligence and academic achievement;

2) Identifying the relationship between creativity and academic achievement;

3) Identifying the relationship between gender and academic achievement.

\section{Research Background}

Jenaabadi [3] investigated the relationship of emotional self-awareness and impulse control, a component of emotional intelligence, with addiction potential of male high school students. This study was carried out to examine the relationship of emotional traits, self-awareness, and impulse control, as psychological characteristics, with addiction potential in order to present appropriate recommendations to prevent the issue. This was a descriptive-correlational study. The statistical population included all male high school students in Zahedan among which 100 male students were selected using random sampling method. Research tools included Emotional SelfAwareness Scale, Emotional Quotient Inventory (Bar-On), and Addiction Potential Scale (APS). To examine the relationship between the variables, obtained data was analyzed using Pearson correlation coefficient. The results indicated that there were negative significant relationships between emotional self-awareness and addiction potential $(-0.391)$ and between impulse control and addiction potential $(-0.582)$. Therefore, it was concluded that one of the methods of creating resistance against drug abuse among students was strengthening their emotional intelligence, especially self-awareness and impulse control.

Isazadegan, Jenaabadi, and Sa'adatmand [4] examined the relationship of cognitive emotion regulation strategies, emotional creativity and academic performance with university students' mental health. This study was conducted to determine and predict mental health through considering cognitive emotion regulation strategies, emotional creativity and academic performance. In this study, the sample included 361 university students (191 females and 170 males) whom were selected among the students of Urmia University through applying stratified random sampling method. The subjects were evaluated using Cognitive Emotion Regulation Strategies Scale, Emotional Creativity Inventory and Mental health Checklist. To analyze the obtained data, Pearson correlation coefficient and stepwise regression analysis were used. The results demonstrated that mental health was significantly and negatively correlated with dimensions of inefficient cognitive emotion regulation strategies, self-de- 
precation, considering issues as catastrophic and blaming others. Moreover, there was no significant relationship between emotional creativity and mental health. Additionally, academic performance and mental health were significantly and positively correlated. Among the variables under the study, self-deprecation, considering issues as catastrophic, blaming others and academic performance explained $26 \%$ of the variance of mental health. The findings of this study indicated that mental health had a negative correlation with inefficient cognitive emotion regulation strategies and had a positive relationship with high academic performance. Moreover, there was no significant correlation between mental health and emotional creativity.

Pirkhanefi and Rafieeian [5], in a study entitled "Examining the Relationship between Emotional Intelligence and Mental Health of Elementary School Teachers in Behshahr", indicated that there was a significant relationship among components of emotional intelligence and mental health of elementary school teachers. The results of regression analysis demonstrated that the variable of emotional intelligence could predict teachers' mental health.

Bakhshi [6] conducted a study to investigate the relationship of emotional intelligence and mental health with organizational commitment of teachers, nurses and staff. The results of the Pearson correlation coefficient showed that emotional intelligence and mental health were correlated significantly and positively with organizational commitment. The results of regression analysis indicated that emotional intelligence and mental health could positively and significantly predict organizational commitment of employees of these three jobs.

Kohsar Haddadi [7], in a study entitled "The Relationship of Emotional Intelligence with Cognitive Mental Health and Academic Achievement”, indicated that components of emotional intelligence were significantly correlated with cognitive mental health and academic achievement of male and female university students. On the other hand, the difference between male and female university students considering the correlation of emotional intelligence with cognitive mental health and academic achievement was significant.

In another study, Samari and Tahmasbi [8] examined the relationship between emotional intelligence and academic achievement in university students and asserted that the overall scores of emotional intelligence and some components of emotional intelligence were significantly related to academic achievement. Moreover, age was significantly correlated with emotional intelligence and its components. With regard to the relationship between emotional intelligence and gender, the results of this study indicated that no significant difference was found between males and females considering their overall scores of emotional intelligence.

Ciarrochi, Deane, and Anderson [9] carried out a study entitled "Emotional Intelligence Moderates the Relationship between Stress and Mental Health". To perceive the relationship among emotional intelligence, stress, and mental health, a study was conducted on 302 university students using a cross-sectional method. The results showed that adults and individuals, who were good in managing and controlling their own and others' feelings and emotions, had more social support and were more satisfied compared to others. This support plays a significant protective role against depression, anxiety, and other psychological problems.

Mayer, Salovey, and Caruso [10] examined gifted students' emotional intelligence and reported that students who had higher emotional intelligence were more capable of recognizing their own and others' feelings and using this knowledge in guiding their behaviors and being resistance to their peer pressure, compared to others. All these elements lead to an increase in individual's social skills. Among personality differences between gifted students and students with learning disabilities, the fact that gifted students, compared to the other group, had more social skills, verbal skills, intelligence, internal control and self-esteem can be stated.

Van der Zee, Thijs, and Schakel [11] conducted a study on 116 university students aged between 18 - 23 years old to examine the relationship between emotional intelligence and academic intelligence and stated that there was a weak relationship between emotional intelligence and academic achievement; however, emotional intelligence was significantly correlated with some personality variables such as extraversion.

Guilford and Chiristensen [12] studied the relationship between emotional intelligence and academic achievement and demonstrated that there was a strong correlation between intelligence and creativity; however, this correlation was not observed when the IQ was higher than 120.

\section{Methods}

The statistical population of this descriptive-correlational study included all second period high school students of Nikshahar. Simple random sampling method was used and based on Morgan table, the sample size was determined 318 individuals. 
To collect data, the following questionnaires were used:

Mayer Salovey Caruso Emotional Intelligence Test (1995): This 30-item scale evaluates emotional intelligence and contains three components of considering emotions, disclosing emotions and constructing mood and is scored using a Likert-type scale ( 1 = strongly disagree, 5 = strongly agree). Cronbach's alpha coefficient of this test was examined in a pilot implementation and for considering emotions, disclosing emotions, and constructing mood, the Cronbach's alpha coefficient was $85 \%, 77 \%$, and $70 \%$, respectively. In this test, items 2 , 3 , $4,7,10,12,17,18,21,23,24$, and 29 relate to considering emotions and items $5,6,11,14,15,16,20,22,25$, 28, and 30 associate with disclosing emotions and items $1,8,9,13,19$, and 26 related to constructing mood.

Creativity Questionnaire: This questionnaire includes 40 questions developed by Sultani. This is a four-point Likert-type scale.

To determine students’ academic achievements, their GPAs in the academic year 2013-2014 were considered.

\section{Validity and Reliability}

\subsection{Validity}

To this end, after developing the initial version of the questionnaire taking educational specialists, university professors, and experts' viewpoints into the consideration, the questionnaire's validity was confirmed.

\subsection{Reliability}

The questionnaires' reliability was calculated for 30 individuals, whom were selected randomly, using Cronbach's alpha coefficient through applying statistical analysis software. Cronbach's alpha coefficient of Emotional Intelligence Test was 88\%. For Creativity Questionnaire, Cronbach's alpha coefficient was 80\%, indicating that these questionnaires have high reliabilities.

The obtained data was analyzed using both descriptive and inferential statistics. In the descriptive level, frequency, mean, standard deviation were applied and in the inferential level, independent t-test and Pearson correlation coefficient were used.

\subsection{Data Analysis}

Table 1 provided overall statistical indices information related to the variables including indices of central tendency, indices of dispersion trends and indices of distribution. The highest mean was for creativity.

Table 2 demonstrated percentage frequency distribution of respondents based on gender indicating that the total number of subjects was 318 individuals, 190 male respondents (59.7\%) and 128 female respondents (40.3\%).

Table 3 demonstrated percentage frequency distribution of respondents based on age indicating that 189 students (59.4\%) were 14 - 16 years old and 129 students (41.6\%) were 17 - 19 years old.

Table 1. Statistical indices related to the variables under study.

\begin{tabular}{cccccccccc}
\hline \multirow{2}{*}{ Variable } & \multicolumn{3}{c}{ Indices of central tendency } & \multicolumn{2}{c}{ Indices of dispersion trends } & \multicolumn{3}{c}{ Indices of distribution } \\
\cline { 2 - 9 } & Mode & Median & Mean & Range & Variance & SD & SK & Kurtosis \\
\hline Emotional intelligence & 5 & 4.5 & 3.421 & 3.14 & 0.223 & 0.470 & -1.230 & 1.876 \\
Creativity & 5 & 4.132 & 4.212 & 3.15 & 29 & 0.450 & -0.525 & 0.321 \\
Academic achievement & 44 & 4.2 & 3.211 & 3.10 & 29 & 0.501 & -0.565 & -0.367 \\
\hline
\end{tabular}

Table 2. Percentage frequency distribution of respondents based on gender.

\begin{tabular}{ccccc}
\hline & Variable & & Frequency & Percentage \\
\hline \multirow{2}{*}{ Gender } & Males & Females & 190 & $59.7 \%$ \\
& & & 128 & $40.3 \%$ \\
& Total & & 318 & $100 \%$ \\
\hline
\end{tabular}


Table 4 demonstrated the frequency distribution of the sample indicating that 130 students (40.8\%) studied in the first grade, 80 students (25.2\%) were in the second grade, 72 students (22.7\%) studied in the third grade and 36 individuals (11.3\%) were in the fourth grade.

\section{Results}

First question: Is there a relationship between emotional intelligence and academic achievement of students? To answer this question, the related results are presented in the following table.

The results demonstrated in Table 5 indicate that the respondents' mean considering their emotional intelligence is 27.95 and standard deviation is 11.18 . With regard to respondents' academic achievement, their mean is 17.62 and standard deviation is 1.67 . The above table shows that the correlation coefficient of emotional intelligence and academic achievement is $r=0.69$ indicating a significant and positive relationship at the 95 percent confidence level $(\mathrm{P}<0.05)$. Therefore, it can be concluded that there is a statistically positive and significant relationship between emotional intelligence and academic achievement of students.

Second question: Is there a relationship between creativity and academic achievement of students?

To answer this question, the results are presented in the following table.

The results demonstrated in Table 6 indicate that the respondents' mean considering their creativity is 23.34 and standard deviation is 9.38. With regard to respondents' academic achievement, their mean is 17.62 and standard deviation is 1.67 . The above table shows that the correlation coefficient of creativity and academic achievement is $\mathrm{r}=0.63$ indicating a significant and positive relationship at the 95 percent confidence level $(\mathrm{P}<$ 0.05). Therefore, it can be concluded that there is a statistically positive and significant relationship between creativity and academic achievement of students.

Third question: Is there a relationship between emotional intelligence and creativity of students?

To answer this question, the related results are presented in the following table.

Table 7 demonstrated the results of correlation coefficient of creativity and emotional intelligence. As it can be seen, the correlation is significant at the 90 percent confidence level $(\mathrm{P}<0.010)$. Therefore, it can be concluded that there is a statistically significant relationship between emotional intelligence and creativity of students.

Table 3. Percentage frequency distribution of respondents based on age.

\begin{tabular}{ccccc}
\hline & & Vrequency & Percentage \\
\hline \multirow{2}{*}{ Age } & & $14-16$ & 189 & $59.4 \%$ \\
& $17-19$ & 129 & $41.6 \%$ \\
& & 318 & $100 \%$ \\
\hline
\end{tabular}

Table 4. Frequency distribution of level of education of the sample.

\begin{tabular}{|c|c|c|c|}
\hline \multicolumn{2}{|c|}{ Variable } & \multirow{2}{*}{$\begin{array}{c}\text { Frequency } \\
130\end{array}$} & \multirow{2}{*}{$\begin{array}{c}\text { Percentage } \\
40.8 \%\end{array}$} \\
\hline \multirow{4}{*}{ Educational level } & First grade & & \\
\hline & Second grade & 80 & $25.2 \%$ \\
\hline & Third grade & 72 & $22.7 \%$ \\
\hline & Fourth grade & 36 & $11.3 \%$ \\
\hline \multicolumn{2}{|c|}{ Total } & 318 & $100 \%$ \\
\hline
\end{tabular}

Table 5. The results of Pearson correlation coefficient of emotional intelligence and academic achievement.

\begin{tabular}{ccccc}
\hline Variables & $\mathrm{N}$ & Mean & SD & R \\
\hline Emotional intelligence & 318 & 27.95 & 11.18 & $0.69^{*}$ \\
Academic achievement & 318 & 17.62 & 1.67 & 0.029 \\
\hline
\end{tabular}


The results demonstrated in Table 8 indicate that male students' mean considering their academic achievement is 17.80 and standard deviation is 1.60 and female students' mean is 17.99 and standard deviation is 1.60. Moreover, the findings indicate that calculated $t$ is equal to 0.727 which is not significant statistically $(\mathrm{P}>0.01)$. Therefore, it can be concluded that there is no difference between male and female students' academic achievement.

\section{Discussion and Conclusion}

Considering the first question, i.e. is there a relationship between emotional intelligence and academic achievement of second period students in Nikshahr?, the results indicated that there was a significant relationship between emotional intelligence and academic achievement of students at the 95 percent significance level. These findings are in line with the results of Rahnama and Abulmaleki [13]. The impact of emotional intelligence on academic and vocational achievement indicated that in many cases emotional intelligence plays a more important role compared to cognitive intelligence. These findings are not consistent with the results of Van der Zee, Thijs, and Schakel [11] in which examining the relationship between emotional intelligence and academic achievement of 116 university students aged between 18 - 23 demonstrated that there was a poor correlation between emotional intelligence and academic achievement; however, the relationship of emotional intelligence with some personality characteristics, such as extraversion, was significant.

With regard to the second question, i.e. is there a relationship between creativity and academic achievement of second period students in Nikshahr?, the results indicated that there was a significant relationship between creativity and academic achievement of students at the 95 percent significance level. These findings are in line with the results of Guilford and Chiristensen [12] and Hassanzadeh and Imanfar [14]. The latter aimed to examine the relationship of creativity and self-esteem with academic achievement in teenagers and young adults using a correlational method. The population included all second grade high school students studying in mathematics-physics and science fields. The statistical sample included 80 male and female students applying stratified sampling method. The results indicated that there was no difference among students studying different academic fields considering their creativity, self-esteem and academic achievement. Additionally, there was no significant relationship between creativity and gender. The correlation coefficient of self-esteem and creativity was higher than that of self-esteem and academic achievement and was also higher than the correlation of creativity with academic achievement.

Considering the third question, i.e. is there a relationship between emotional intelligence and creativity of second period high students in Nikshahr?, the results indicated that there was a significant relationship between emotional intelligence and creativity of students at the 90 percent significance level. These findings are in line with the results of Jenaabadi [3] and Tashakkori (2005) as cited in Pirkhanefi and Rafieeian [5], showing that

Table 6. The results of correlation coefficient of creativity and academic achievement.

\begin{tabular}{ccccccc}
\hline Variables & $\mathrm{N}$ & Mean & $\mathrm{SD}$ & $\mathrm{r}$ & Sig \\
\hline Creativity & 318 & 23.34 & 9.38 & & $0.63^{*}$ & 0.049 \\
Academic achievement & 318 & 17.62 & 1.67 & & \\
\hline
\end{tabular}

Table 7. The results of Pearson correlation coefficient of emotional intelligence and creativity.

\begin{tabular}{ccc}
\hline Correlation coefficient & Level of significance & $\mathrm{N}$ \\
\hline 0.55 & P-value $<0.08$ & 318 \\
\hline
\end{tabular}

Table 8. The results of independent t-test to examine the difference between male and female students' academic achievement.

\begin{tabular}{cccccc}
\hline Variables & Students & N & Mean & SD & T \\
\hline & Male & 190 & 17.80 & 1.60 & 0.727 \\
Academic achievement & Female & 128 & 17.99 & 1.60 & \\
\hline
\end{tabular}


intelligence and creativity were not significantly related to students' interests.

With regard to the fourth question, i.e. is there a difference between male and female second period high school students' academic achievement in Nikshahr?, the results indicated that there was no difference between male and female second period high school students. These findings are in line with the results of Isazadegan, Jenaabadi, and Sa'adatmand [4].

\section{References}

[1] Mirhashemi, M., Pasha Sharifi, H. and Sabeti, Sh. (2008) Relationship between Emotional Intelligence and Job Involvement. Journal of Thought and Behavior, 3, 26-17. (In Persian)

[2] Shamoradlou, M. (2004) Comparing the Role of Emotional Intelligence and Cognitive Intelligence in Predicting Academic Achievement of Pre-University Students in Tehran. MSc Thesis, Shahid Beheshti University, Tehran.

[3] Jenaabadi, H. (2012) Examining the Relationship of Emotional Self-Awareness and Impulse Control, a Component of Emotional Intelligence, with High School Students’ Addiction Potential. Educational Psychology Studies, 7, 1-12.

[4] Isazadegan, A., Jenaabadi, H. and Sa'adatmand, S. (2014) The Relationship of Cognitive Emotion Regulation Strategies, Emotional Creativity, and Academic Achievement with Mental Health. Educational Psychology Studies, 3, 71-92.

[5] Pirkhanefi, A.R. and Rafeeian, H. (2012) Examining the Relationship between Emotional Intelligence and Mental Health of Elementary School Teachers in Behshahr. Journal of Initiative and Creativity in the Humanities, 1, 35-42.

[6] Bakhshi, L. (2010) The Relationship of Emotional Intelligence and Mental Health with Organizational Commitment of Teachers, Nurses and Staff. Journal of New Findings in Psychology, 2, 23-33.

[7] Kohsar Haddadi, A.A. (2004) Assessing the Relationship of Emotional Intelligence and Mental Health with Academic Achievement of Shahed and Normal Students Studying in Tehran University. MA Thesis, Shahed University, Tehran.

[8] Samari, A.A. and Tahmasebi, F. (2007) Investigating the Relationship between Emotional Intelligence and Academic Achievement of University Students. Journal of Mental Health, 9, 35-36.

[9] Ciarrochi, J.P., Deans, F. and Anderson, S. (2000) Emotional Intelligence Moderates the Relationship between Stress and Mental Health. Journal of Personality and Individual Differences, 32, 197-209. http://dx.doi.org/10.1016/S0191-8869(01)00012-5

[10] Mayer, J.D., Salovey, P. and Caruso, D. (2000) Selecting a Measure of Emotional Intelligence, Hard Book of Emotional Intelligence. Bass Inc., California.

[11] Van der Zee, K., Thijs, M. and Schakel, L. (2002) The Relationship of Emotional Intelligence with Academic Intelligence and the Big Five. European Journal of Personality, 16, 103-125. http://dx.doi.org/10.1002/per.434

[12] Guilford, J.P. and Chiristensen, P. (1973) The One-Way Relation between Creative Potential and IQ, Journal of Creative Behavior, 22, 247-252. http://dx.doi.org/10.1002/j.2162-6057.1973.tb01096.x

[13] Rahnama, A. and Abdulmaleki, J. (2009) The Relationship of Emotional Intelligence and Creativity with Academic Achievement of Shahed University Students. Journal New Educational Thoughts, 2, 55-78.

[14] Hassanzadeh, R. and Imanifar, P. (2011) The Relationship of Creativity and Self-Esteem with Academic Achievement Teenagers and Young Adults. Academic Journal of Sociology, 1, 92-99. 